\title{
Mechanical and deformation characteristics of composite assembled supporting structure
}

\section{Chengchao Guo PhD}

Associated Professor, School of Civil Engineering, Sun Yat-sen University,

Zhuhai, China; Guangdong Key Laboratory of Oceanic Civil Engineering,

Guangzhou, China; Guangdong Research Center for Underground Space Exploitation Technology, Guangzhou, China; Southern Marine Science and Engineering Guangdong Laboratory (Zhuhai), Zhuhai, China; Southern Institute of Infrastructure Testing and Rehabilitation Technology, Huizhou, China

Juntao Ye BD

Graduate student, School of Civil Engineering, Sun Yat-sen University, Zhuhai, China

\begin{abstract}
Chenyang Zhao PhD
Assistant Professor, School of Civil Engineering, Sun Yat-sen University, Zhuhai, China; Guangdong Key Laboratory of Oceanic Civil Engineering, Guangzhou, China; Guangdong Research Center for Underground Space Exploitation Technology, Guangzhou, China; Southern Marine Science and Engineering Guangdong Laboratory (Zhuhai), Zhuhai, China (Orcid:00000002-1998-3962) (corresponding author: zhaochy28@mail.sysu.edu.cn)

Fuming Wang PhD

Professor, School of Civil Engineering, Sun Yat-sen University, Zhuhai, China; Guangdong Key Laboratory of Oceanic Civil Engineering, Guangzhou, China; Guangdong Research Center for Underground Space Exploitation Technology, Guangzhou, China; Southern Marine Science and Engineering Guangdong Laboratory (Zhuhai), Zhuhai, China; Southern Institute of Infrastructure Testing and Rehabilitation Technology, Huizhou, China
\end{abstract}

The composite assembled recyclable supporting structure is a type of newly developed supporting structure; it combines a steel skeleton supporting structure with polymer waterproof technology. Based on the Niukouyu excavation project in Zhengzhou, China, a three-dimensional finite-element model is established to simulate the excavation process using this type of supporting structure. The effects of important design factors (foundation pit depth, length-to-width ratio and steel beam interval) on lateral displacements and bending moments of the supporting pile in the worst scenario are analysed. The results show that the composite assembled recyclable supporting structure can effectively control the deformation of the excavation. The supporting pile has an inward deformation mode. Both maximum lateral displacement and bending moment

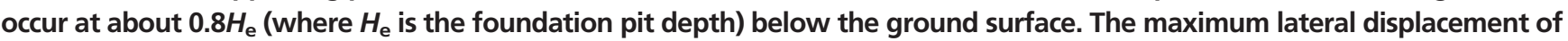
the supporting pile ranges from $0.023 \% H_{\mathrm{e}}$ to $0.12 \% H_{\mathrm{e}}$. Furthermore, a global sensitivity analysis is also conducted to distinguish the relative importance of uncertain soil parameters (elastic stiffness and shear strength) on the system behaviour in this Niukouyu project. It is found that the elastic modulus of soil dominates the supporting structure responses, while the soil shear strength plays an insignificant role in determining the system behaviour due to negligible plastic deformations.

\section{Notation}

A, B

C

$c_{2}$

$c_{4}$

$D_{\text {max }}$

$D_{\text {top }}$

E

$E_{2}$

$E_{4}$

H

$H_{\mathrm{e}}$

$H_{\mathrm{p}}$

h

i

$L / B$

$M_{\max }$

$n$

$R^{2}$

$S_{\mathrm{T} j}$

$\boldsymbol{y}_{\mathrm{A}}, \boldsymbol{y}_{\mathrm{B}}, \boldsymbol{y}_{\mathrm{C} j}$

$\alpha$

$\gamma$ two independent $(N, k)$ matrices

cohesion of soil

cohesion of soil layer 2

cohesion of soil layer 4

maximum lateral displacement

lateral displacement at the top of the pile

elastic modulus

elastic modulus of soil layer 2

elastic modulus of soil layer 4

excavation depth

foundation pit depth

actual length of the pile

depth of the observation point

length-to-width ratio in the initial model

length-to-width ratio

maximum bending moment

number of steel beams

standard error measure

total effect index

vectors containing model evaluations for matrices

$\mathrm{A}, \mathrm{B}$ and $\mathrm{C}_{j}$, respectively

variation in the model response

unit weight $(\mathrm{kN} / \mathrm{m})$ $v \quad$ Poisson's ratio

$\phi \quad$ soil friction angle

$\phi_{2} \quad$ soil friction angle of soil layer 2

$\phi_{4} \quad$ soil friction angle of soil layer 4

\section{Introduction}

Excavations have been widely used for the development of economy and urbanisation. Many researchers have conducted case studies (Blackburn and Finno, 2007; Liu et al., 2011), statistical analysis ( $\mathrm{Li}$ et al., 2015; Xu et al., 2008) and numerical simulation (Cheng and Likitlersuang, 2018; Hsiung et al., 2018) to investigate the mechanical and deformation characteristics of traditional support structures such as diaphragm walls, row pile support and pile-anchor support. According to the aforementioned studies, traditional supporting structures can meet the requirements of practical excavation of foundation pits, but they also have many limitations, such as having a high cost, easily developing cracks, being difficult to demolish and reducing the utilisation efficiency of underground space.

Regarding the shortcomings of traditional supporting structures, Wang et al. (2018) proposed a rigid-flexible composite recyclable supporting structure that combines a steel skeleton supporting structure with flexible waterproof polymers. This kind of composite 
Mechanical and deformation

characteristics of composite assembled

supporting structure

Guo, Ye, Zhao and Wang assembled recyclable supporting structure has the advantages of good stability, efficient construction process, recyclable usage and low cost. Wang (2018) analysed the mechanical deformation behaviour of a prefabricated recoverable row piles support structure in an elliptical foundation pit. Pan et al. (2019) further applied this type of composite recyclable supporting structure to a circular underground granary, which proves its applicability in real projects. However, rectangular foundation pits are more widely utilised in reality. The mechanical and deformation characteristics of the composite assembled recyclable supporting structure in rectangular excavation are still not clear. Therefore, Guo et al. (2020) studied the excavation-induced stresses and deformations of this prefabricated recyclable rectangular retaining system. The in situ measurements were used to calibrate the numerical simulation where representative soil properties in the Zhengzhou region of China were employed. While this study focused on the effect of the pile embedded ratio and the thickness of the steel panel, the influence of the geometrical size of the supporting structure, such as depth and length-to-width ratio, and the uncertainty of the soil profile on the structural behaviour were not evaluated, which can serve as a guideline in engineering practice.

Combined with finite-element (FE) simulation, a parametric study is normally carried out to study the relation between model parameters and system behaviour. Finno et al. (2007) presented 150 sets of FE simulation results and found that when the ratio of the excavated length to the excavated depth is greater than 6 , plane strain simulations yield the same displacements in the centre of the supporting wall as those computed by three-dimensional (3D) simulation. Hsieh and Chien (2018) performed a series of FE analyses to study the relationship between the geometrical parameters and model responses of a supporting system. They pointed out that soil constitutive parameters dominate the soil behaviour and have significant influence on excavation deformation. Knabe et al. (2012) utilised local sensitivity analysis (LSA) to evaluate the important soil parameters for geotechnical problems. Miro et al. (2014) and Zhao et al. (2018) performed global sensitivity analysis (GSA) to determine the key subsoil parameters that influence the tunnelling behaviour. However, since the composite assembled recyclable supporting structure has only been proposed recently, research studies have rarely focused on the influence of geometrical and material parameters on the mechanical and deformation characteristics of the supporting structure.

Based on the Niukouyu foundation pit in Zhengzhou, China, which has been described in the paper by Guo et al. (2020), a modified 3D numerical model of the excavation using a composite assembled recyclable supporting structure is firstly established in the present study. The Mohr-Coulomb (MC) model parameters are determined by way of in situ and laboratory tests. The mechanical and deformation characteristics of the supporting structure during the excavation process are evaluated, and the range of maximum lateral displacement of the representative pile is suggested. After that, a parametric study is conducted to investigate the influences of key factors (namely, foundation pit depth, the length-to-width ratio of excavation and beam interval) on the system behaviour of the supporting structure. Finally, GSA is conducted to distinguish the key soil parameters that affect the behaviour of the supporting structure. This work aims to provide guidelines on the design and construction of foundation pits using the composite assembled recyclable supporting structure in similar projects.

\section{Project background}

Composite assembled recyclable supporting structure The Niukouyu foundation pit is a part of the Yellow River Diversion Project; it is located between Kexue Avenue and the ring expressway in Zhengzhou, China (see Figure 1). This foundation pit has a length of $7.5 \mathrm{~m}$, a width of $4.65 \mathrm{~m}$ and a depth of $11.4 \mathrm{~m}$. The composite assembled recyclable supporting structure is applied to this foundation pit as shown in Figures 2 and 3. To be specific, it consists of cement-steel piles, steel beams, a steel panel and polymer grout. The pile has a length of $15.5 \mathrm{~m}$ and a diameter of $0.6 \mathrm{~m}$. Steel type HW350 is adopted in the pile and beam construction. The steel panel has a thickness of $5 \mathrm{~mm}$. Polymer grout is injected to fill the gap between the steel panel and the surrounding soil. Concrete type C30 is adopted in concrete slab construction, and its thickness is $0.5 \mathrm{~m}$. The in situ construction process of the foundation pit is also shown in Figure 4.

\section{Geological profiles}

According to the in situ geotechnical investigation report, the soil profile in the excavation zone can be categorised into five layers.

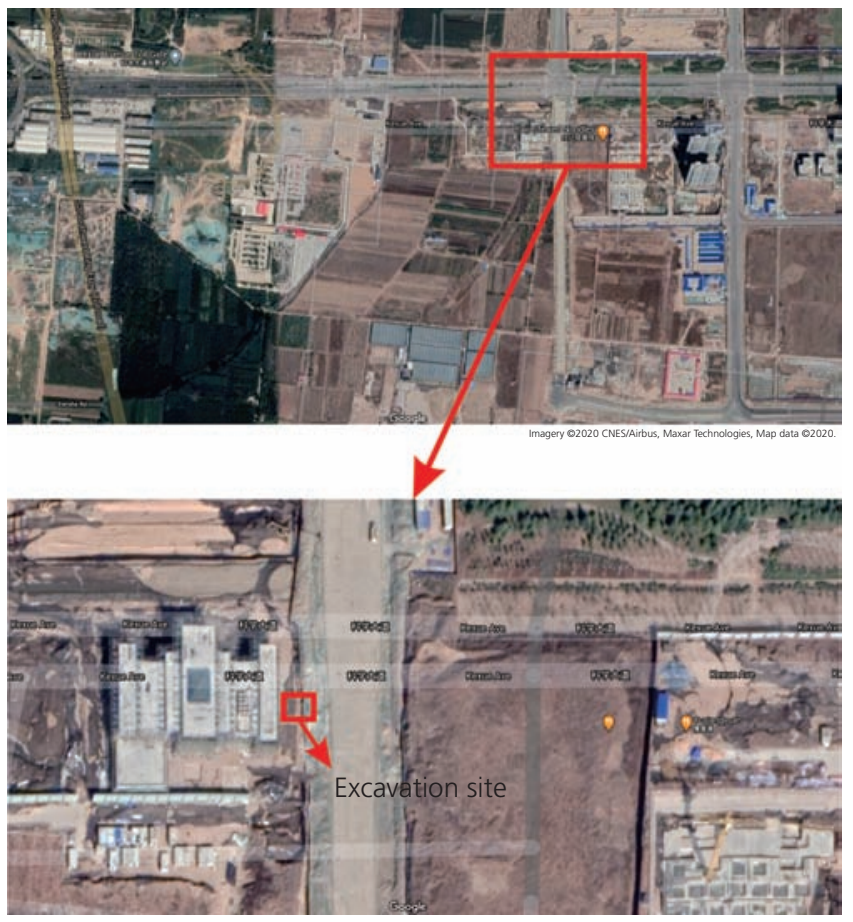

Figure 1. Satellite photographs of the excavation site (source: Google Maps) 
Geotechnical Research

Volume 7 Issue 4
Mechanical and deformation

characteristics of composite assembled

supporting structure

Guo, Ye, Zhao and Wang

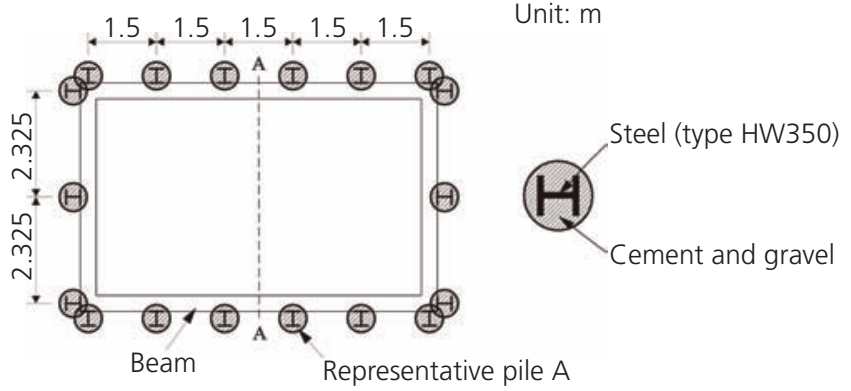

Figure 2. Plan view of the supporting structure; after Guo et al. (2020)

The physical and mechanical properties of these soil layers are presented in Table 1. It is worth mentioning that soil cohesion $c$ and friction angle $\phi$ are determined by laboratory direct shear tests; the elastic modulus $E$ is determined by the oedometer test for soil sample at a certain depth. Poisson's ratio $v$ is obtained from the Geological Engineering Handbook (GEH, 2018). All soil layers are assumed to have no dilatancy. According to the survey report and monitoring results, no groundwater was found in the excavation zone. Hence, the influence of groundwater level is not considered in the present study.

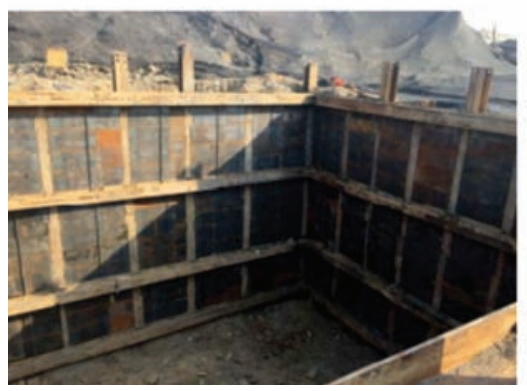

(a)

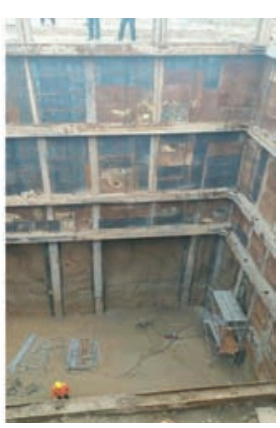

(b)
Figure 4. In situ construction process of the foundation pit: (a) third excavation stage $H=7 \mathrm{~m}$ (left); (b) fourth excavation stage $H=10.9 \mathrm{~m}$

\section{Numerical simulation}

In this study, the 3D excavation process of the Niukouyu foundation pit is modelled by way of FE method (FEM) using the commercial software Abaqus (version 6.14). The geometry and mesh discretisation of the model is shown in Figure 5; only one-fourth of the model is considered due to the symmetric condition. The size of model is designed to be large enough to avoid the boundary effect (Roboski, 2004; Zhao et al., 2015).

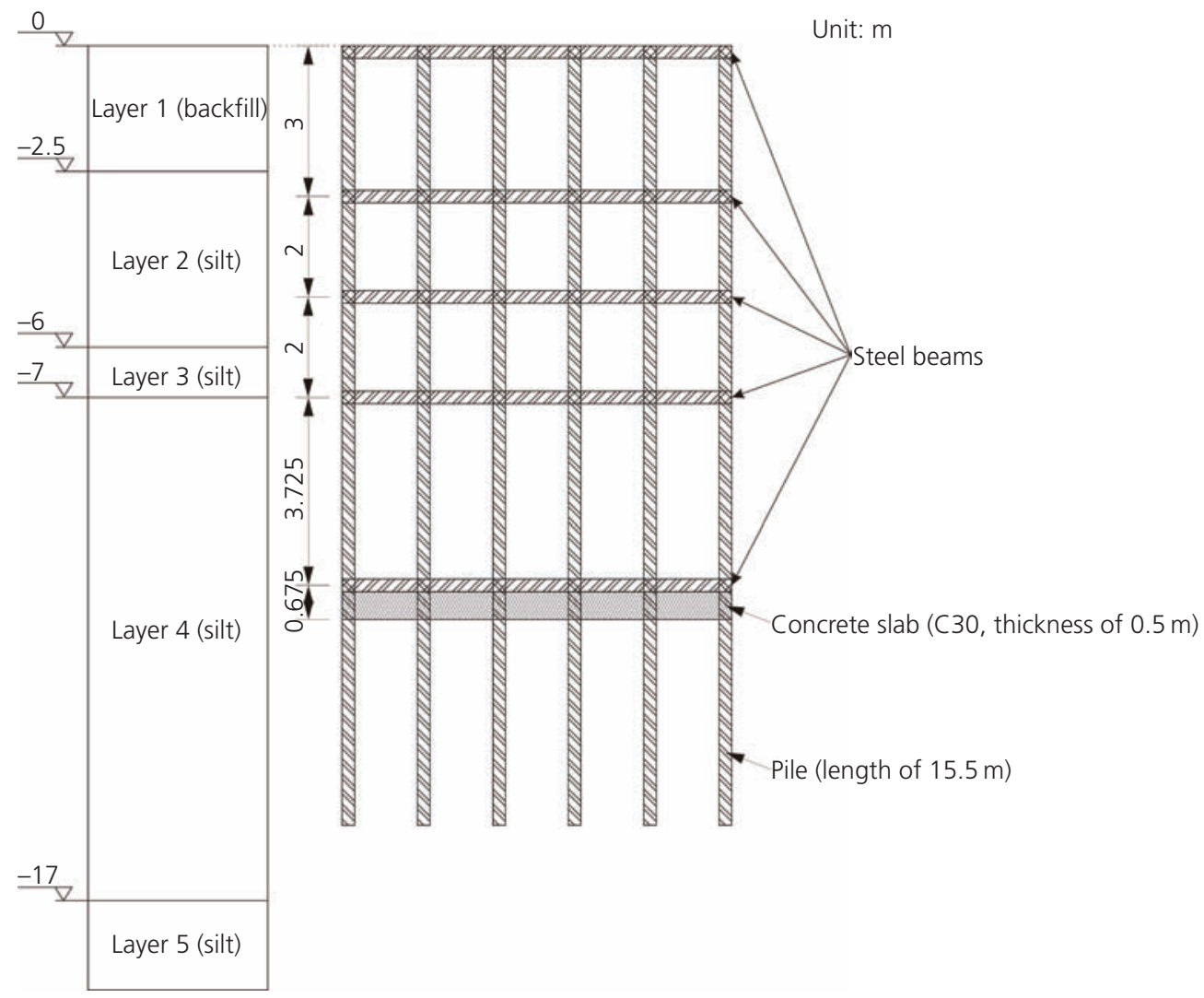

Figure 3. Section view of the supporting structure; after Guo et al. (2020) 
Table 1. Physical and mechanical parameters of the soil

\begin{tabular}{|c|c|c|c|c|c|}
\hline Parameter & Layer 1 (backfill) & Layer 2 (silt) & Layer 3 (silt) & Layer 4 (silt) & Layer 5 (silt) \\
\hline Thickness: $m$ & 2.5 & 3.5 & 1.0 & 10.0 & 1.2 \\
\hline Unit weight, $\gamma: \mathrm{kN} / \mathrm{m}$ & 17.0 & 17.6 & 17.7 & 17.6 & 18.0 \\
\hline Elastic stiffness, E: MPa & 3 & 20 & 35 & 50 & 60 \\
\hline Poisson's ratio, $v$ & 0.3 & 0.3 & 0.3 & 0.3 & 0.3 \\
\hline Cohesion, $\mathrm{c}: \mathrm{kPa}$ & 5.0 & 18.3 & 22.0 & 17.8 & 22.0 \\
\hline Friction angle, $\phi:^{\circ}$ & 15.0 & 19.1 & 21.7 & 23.4 & 18.6 \\
\hline
\end{tabular}

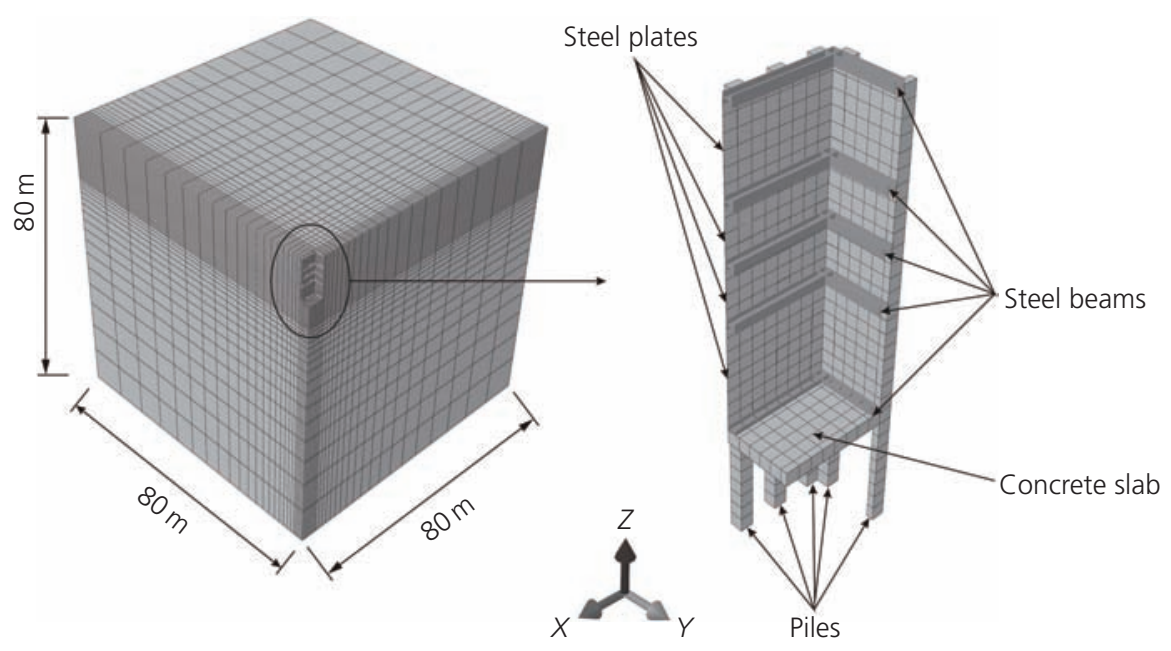

Figure 5. Geometry of the numerical model

In the present model, the total number of model elements is 18 402. The mechanical boundary conditions at the bottom and outer boundaries of the model are defined by restricting the deformations in the normal directions, while the in-plane displacements are allowed. There is no mechanical fixity on the top surface of the model, and the effect of groundwater is not considered.

\section{Constitutive modelling}

In order to describe the soil behaviour, the MC model is adopted in the present study, as limited experimental data are available. Many parameters must be assumed when using an advanced constitutive model (e.g. modified Cam Clay model and hardening soil model). Uncertainties are inevitably induced in this process, which may lead to unrealistic model predictions. In contrast, although $\mathrm{MC}$ is a simple model, all the required constitutive parameters have clear physical meanings and they are realistically measurable in this Niukouyu project. As mentioned in the previous subsection, the required model parameters are obtained by way of laboratory tests, and the soil parameters are given in Table 1. The pile, beam and steel panel are considered elastic materials; therefore, the linear elastic model is applied to reproduce their behaviour. For the sake of simplicity, the pile is modelled as an equivalent rectangular pile $(0.5 \times 0.5 \mathrm{~m})$ using equivalent stiffness (Guo et al., 2020). The detailed material parameters of the support structure are shown in Table 2.
It should be noted that the soil, pile and concrete slab utilise the 3D solid eight-node element (C3D8) in the FE model. The beam utilises the beam element (B31). The steel panel utilises the fournode shell element (S4). In order to model the soil-structure interaction, the surface-to-surface contact between the supporting structure and the soil is taken into account in the FE model. The normal contact utilises the hard contact algorithm, and the tangential contact utilises the penalty function algorithm where the frictional coefficient is defined as 0.35 . It is assumed there is no relative displacement between the pile and the steel panel, as well as between the pile and the beam.

\section{Excavation process}

The excavation process of the designed foundation pit is divided into five steps in reality to keep the deformation of the supporting structure within the tolerance limit. This is shown in Figure 6. In the numerical simulation, initialisation is firstly conducted to generate the geostatic stress before installing the piles and steel beam at the model surface. Thereafter, the first excavation step is

Table 2. Mechanical properties of the supporting structure

\begin{tabular}{lrrrr|} 
Parameter & Pile & Beam & Panel & Slab \\
\hline Unit weight, $\gamma: \mathrm{kN} / \mathrm{m}^{3}$ & 32.0 & 78.0 & 78.0 & 24.0 \\
Elastic stiffness, E: GPa & 36.2 & 210.0 & 210.0 & 30.0 \\
Poisson's ratio, $v$ & 0.2 & 0.2 & 0.2 & 0.3
\end{tabular}




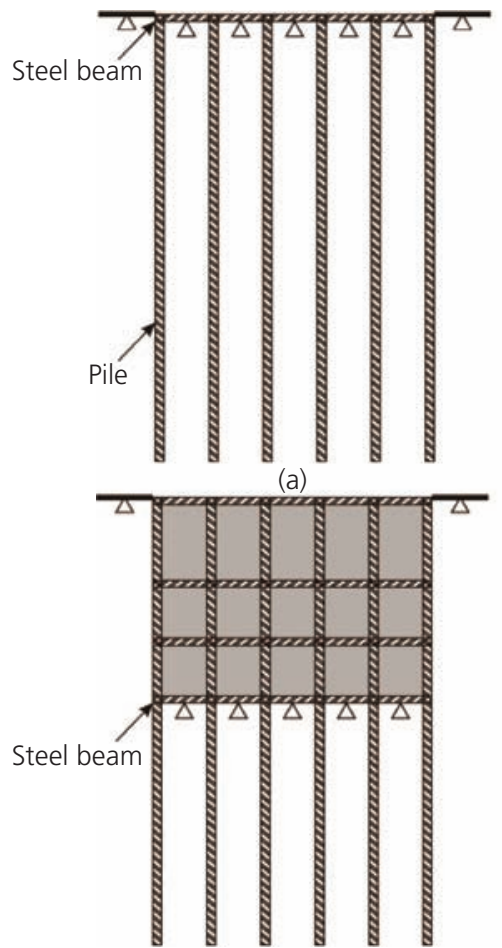

(d)

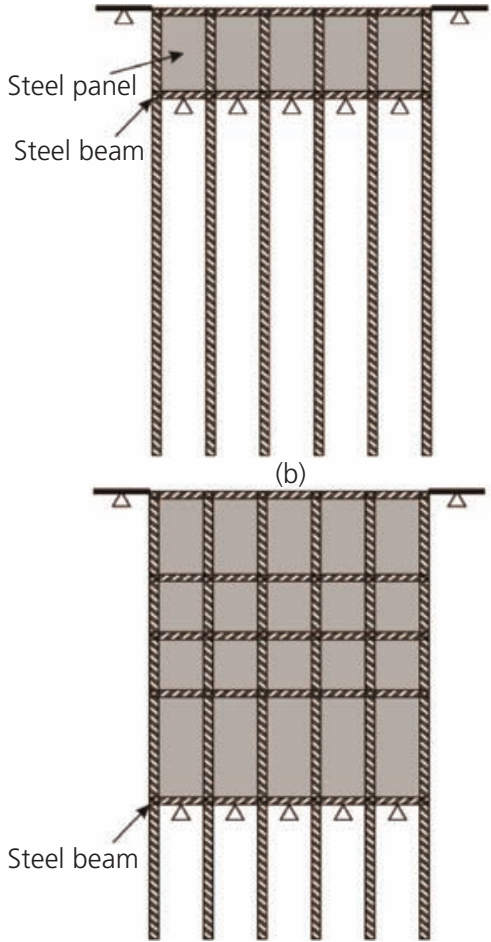

(e)

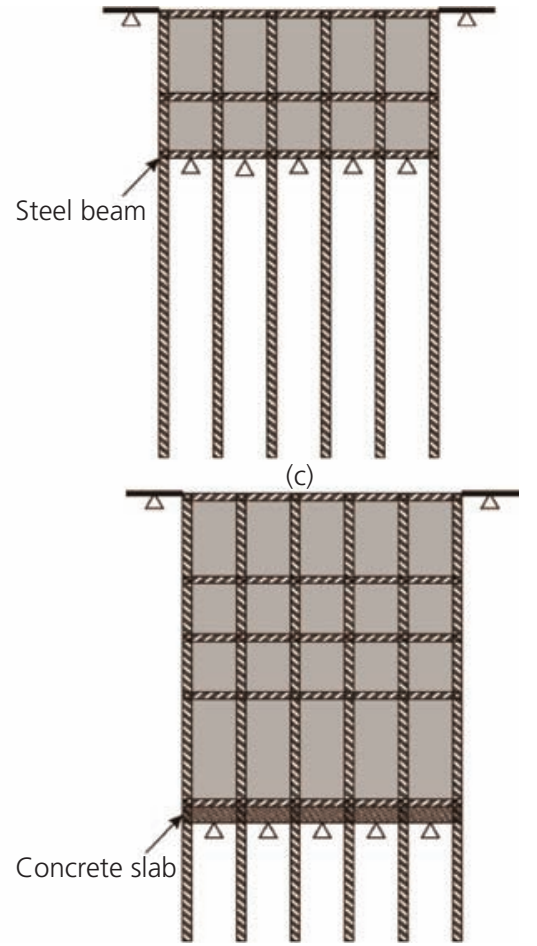

(f)

Figure 6. Illustration of the in situ excavation process: (a) installation of piles and surface steel beams; (b) first excavation stage; (c) second excavation stage; (d) third excavation stage; (e) fourth excavation stage; (f) final excavation stage

conducted up to a depth of $3 \mathrm{~m}$; subsequently, the steel beam is installed at the design depth for this excavation step. By analogy, the second, third and fourth excavation steps are conducted up to depths of 5.0, 7.0 and $10.9 \mathrm{~m}$, respectively. Finally, the concrete slabs are installed by an additional $0.5 \mathrm{~m}$ depth of excavation.

\section{Results and discussion}

According to the geometrical size of the foundation pit, it can be deduced that the middle cross-section at the length direction (section A-A in Figure 2) has the worst scenario. In other words, the largest deformation and structural forces in this cross-section will be observed during the excavation process, which serves as the guideline for structural design. Therefore, the lateral displacements and bending moments for the pile closest to this cross-section (representative pile A in Figure 2) are investigated in the following sections.

\section{Lateral displacements and bending moments of the supporting pile during excavation}

Figure 7 shows the lateral displacements and bending moments of representative pile A during excavation. As seen, the lateral displacements at the top of the pile are negligible due to the fact that the steel beams are installed at the pile top before excavation. Inward displacements of the pile (away from the surrounding soil) are observed since the excavation started. With the excavation going deeper, the maximum lateral displacement of the pile gradually increases, and the corresponding position where the maximum lateral displacement is observed continuously moves downwards. When the excavation is finished $(H=11.4 \mathrm{~m}$, where $H$ is the excavation depth), the maximum lateral displacement of the pile is $3.8 \mathrm{~mm}$, which well matches the field measurements of about $3 \mathrm{~mm}$ (Guo et al., 2020). Moreover, the position of the maximum lateral displacement of the pile occurs at approximately $0.8 H$ below the ground surface.

Figure 8 shows the maximum lateral displacements of pile A for different scenarios (refer to the next subsection) compared with the monitoring results in the literature. As can be seen, the ratio of the maximum lateral displacement and foundation pit depth falls within the range $0.023-0.120 \%$. The measurements of other studies (Guo et al., 2020; Pan et al., 2019) using the same supporting structure are 0.026 and $0.071 \%$, respectively, which fall within the same range. This range and the exact values are generally smaller than those obtained by Clough and O'Rourke (1990) (0.2\%) and Ou et al. (1993) $(0.2-0.5 \%)$. This can be attributed to the fact that the geometrical size of the Niukouyu foundation pit is relatively smaller, and the efficient construction process of the composite assembled recyclable supporting structure results in less deformation.

Furthermore, it is found that the lateral displacement at the bottom of the pile gradually increases with deeper excavation depths, which is caused by the decreasing embedded depth of the pile (Ou et al., 1993). The embedded ratio of the pile (defined as the ratio of the length below the excavation surface to the length above the excavation surface) decreases from 4.16 at the first 
Mechanical and deformation

characteristics of composite assembled

supporting structure

Guo, Ye, Zhao and Wang
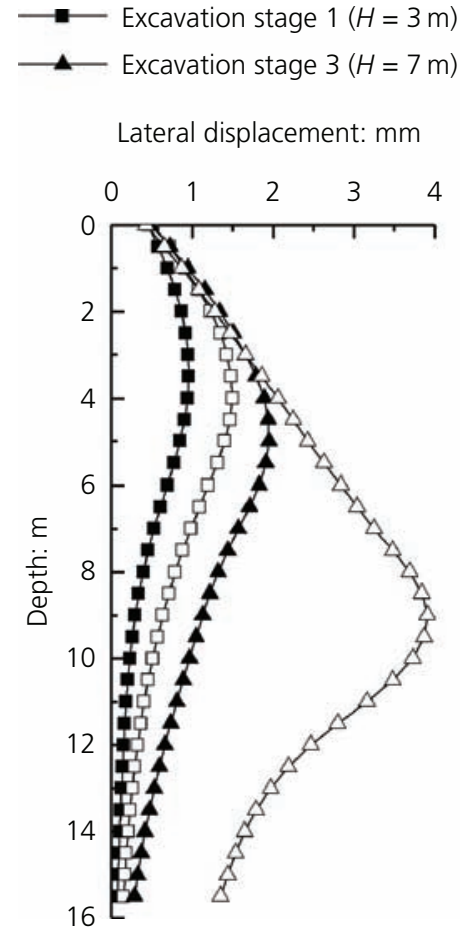

(a)
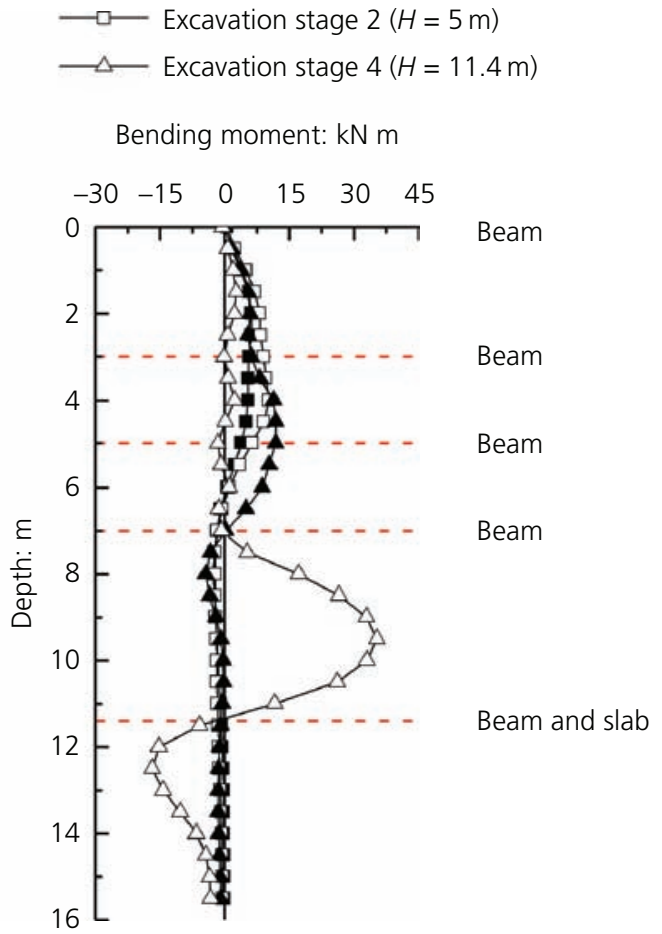

(b)

Figure 7. (a) Lateral displacements and (b) bending moments of the representative pile during excavation

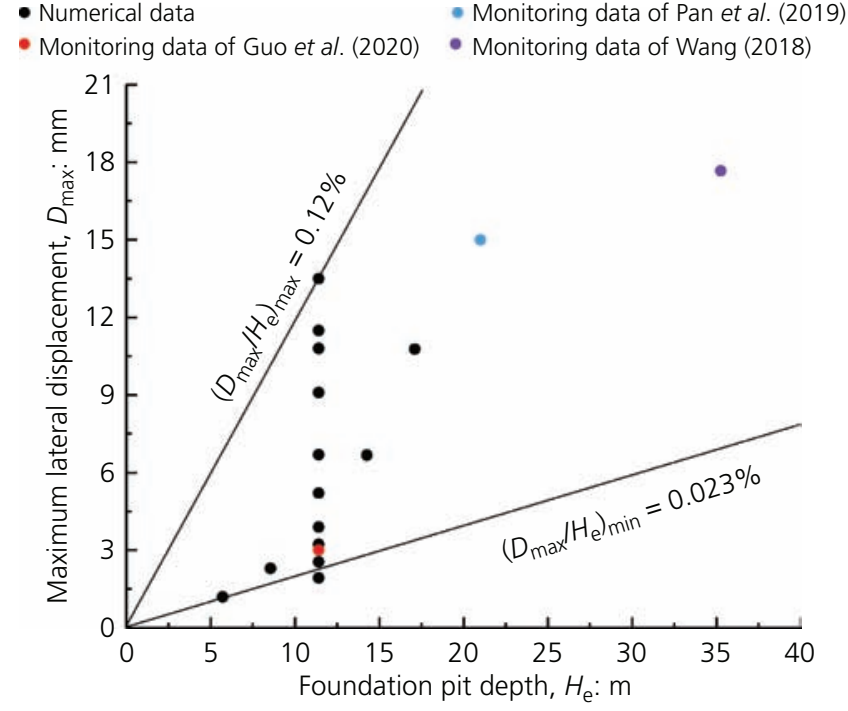

Figure 8. Range of the maximum lateral displacements of the representative pile during excavation

excavation stage $(H=3 \mathrm{~m})$ to 0.36 by the end of the final excavation stage $(H=11.4 \mathrm{~m})$.

According to Figure 7, during the excavation process, the maximum bending moment of the pile gradually increases and its position moves downwards continuously. As seen, the position where maximum bending moments are observed coincides with the position where the maximum lateral displacement of the pile occurs. This is because the bending moment is the second derivative of its lateral deformation. Moreover, the positive bending moments occur on the upper part of the pile above the excavation surface due to the effect of active earth pressure and inward movements of the pile, while for the lower part of the pile, negative bending moments are observed. This is caused by the restriction of the soil in the passive earth pressure zone; subsequently, the bending moment distribution of the pile at the beam position has an inflection phenomenon. To be specific, the inflection point of the bending moment distribution always occurs next to the excavation surface of the foundation pit, which is attributed to the strong resistance effect of the newly installed steel beam and the embedded pile. This is consistent with the findings of Pan et al. (2019) using the same type of supporting structure.

\section{Influencing factors affect the lateral displacements and bending moments of the pile}

Based on the preliminary study, the authors find that the foundation pit depth $\left(H_{\mathrm{e}}\right)$, length-to-width ratio $(L / B)$ and number of steel beams $(n)$ play a vital role in determining the behaviour of the supporting structure during excavation. Within this framework, their influences on the deformation and bending moments of representative pile A are investigated. 


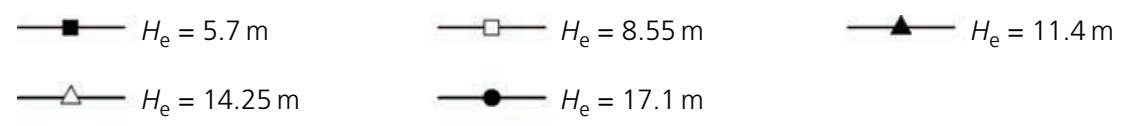

Lateral displacement: $\mathrm{mm}$

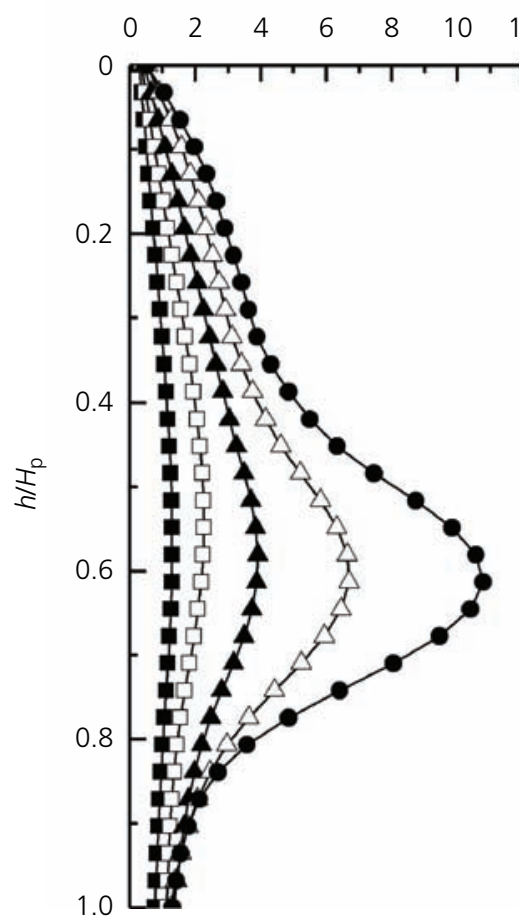

(a)

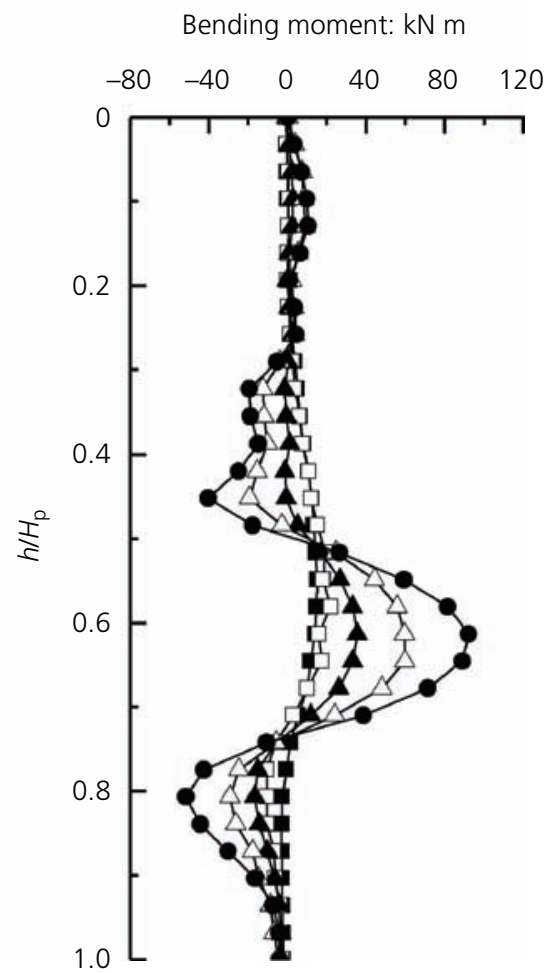

(b)

Figure 9. Effect of the foundation pit depth on the (a) lateral displacements and (b) bending moments of the representative pile

\section{Effect of the foundation pit depth}

As mentioned before, the embedded ratio of the pile is a key parameter that controls its deformation and forces. In this part of the study, the embedded ratio is kept constant as 0.36 (refer to the previous section) when varying the foundation pit depth. In addition to the initial model, another four scenarios are considered where the foundation pit depth is $0.50,0.75,1.25$ and 1.50 times that in the initial model, to analyse the influence of the excavation depth on the responses of representative pile A.

Figure 9 shows the lateral displacements and bending moments of representative pile A with different foundation pit depths $\left(H_{\mathrm{e}}\right)$. It should be noted that the vertical axis is normalised based on the actual length of the pile $\left(H_{\mathrm{p}}\right)$ and $h$ represents the depth of the observation point. The number of steel beams and their interval ratios in all scenarios are identical to those in the initial model.

As seen in Figure 9, the lateral displacements of pile increase with increasing foundation pit depth. The lateral displacement in the lower part of the pile increases exponentially with a deeper foundation pit. The authors further display the maximum lateral displacement of the representative pile $\left(D_{\max }\right)$ with increasing foundation pit depth in
Figure 10. As can be seen from the figure, a polynomial equation can well describe their correlation. This is consistent with the

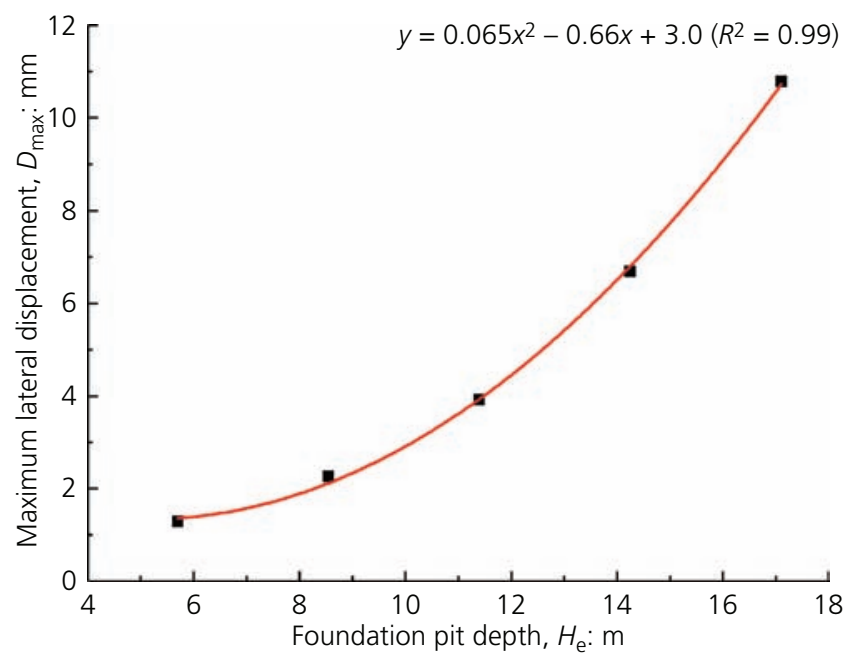

Figure 10. Effect of the foundation pit depth on the maximum lateral displacement 
Mechanical and deformation

characteristics of composite assembled

supporting structure

Guo, Ye, Zhao and Wang findings of $\mathrm{Xu}$ et al. (2018). As the steel beam is relatively rigid compared with the deformable soil at the surface level, the deformation at the upper part of the pile is restricted, while for the deeper part of the pile, the lateral earth pressure increases and results in larger displacements. For the bottom part of the pile that is embedded in the soil, the lateral displacement is negligible.

By analogy, the bending moment of the pile also increases with a deeper foundation pit. It is observed that the local inflection of the bending moment distribution always occurs at the positions where steel beam is installed. As the steel beam adopted in this project has identical stiffness, lower and higher bending moments are observed at the upper and lower parts of the pile, respectively. Consider the earth pressure variation along the depth in reality; it is suggested to apply a steel beam with relatively low stiffness at the top of the foundation pit to save costs, while for the deeper part of the foundation pit, a steel beam with a high stiffness should be utilised to control the lateral displacements within the tolerance limit. The supporting pile should be inserted into the stiff soil layer (e.g. stiff clay and rock) to restrict the lateral displacements of the pile. Additionally, it is found that both maximum lateral displacement and bending moment occur at about $0.6 H_{\mathrm{p}}$ below the ground surface, where $H_{\mathrm{p}}$ represents the length of the pile (this coincides with aforementioned $0.8 H$ ).

\section{Effect of the length-to-width ratio}

Consider the 3D geometrical size of the foundation pit; the spatial effect of the supporting structure should be taken into account. To be specific, the middle plane in the length direction of the foundation pit tends to plane strain condition when the length-towidth ratio $(L / B)$ becomes greater. In contrast, the spatial effect becomes significant with small $L / B$ values. Within this framework, this part of the study aims to investigate the influence of the lengthto-width ratio on the responses of representative pile A.

Figure 11 shows the lateral displacement and bending moment profiles of representative pile A under different values of $L / B$. Here $i$ represents the length-to-width ratio in the initial model, and the width of the foundation pit is kept constant. As seen in Figure 11, with increasing length-to-width ratio, the lateral displacements of the pile gradually increase, and the position where the maximum lateral displacement is observed moves upwards. Furthermore, Figure 12 shows the maximum lateral displacement with increasing length-to-width ratio. A logarithmic

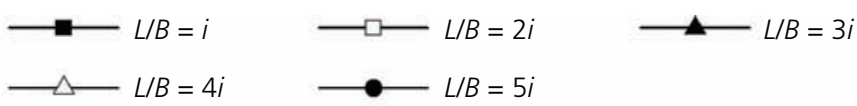

Lateral displacement: $\mathrm{mm}$

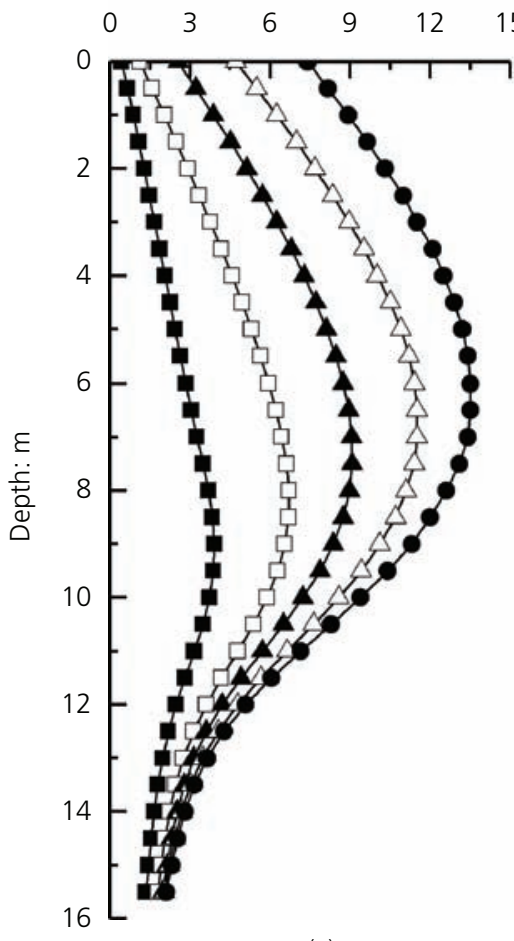

(a)
Bending moment: kN m

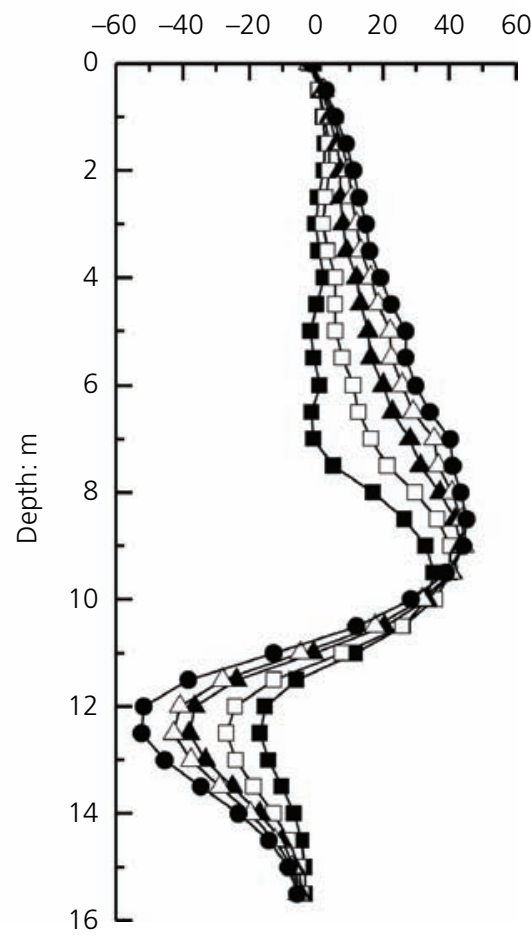

(b)

Figure 11. Effect of the length-to-width ratio on the (a) lateral displacements and (b) bending moments of the representative pile 


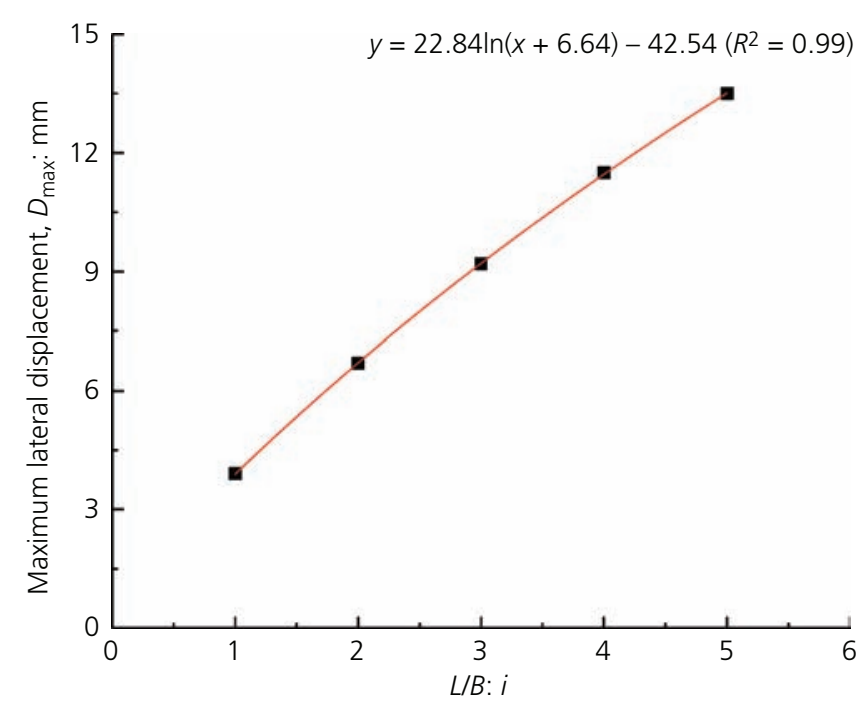

Figure 12. Effect of the length-to-width ratio on the maximum lateral displacement

equation can be obtained to approximate their correlation. Additionally, it is found that the lateral displacement at the upper part of the pile increases faster with increasing $L / B$. This is different compared with the result of Xu et al. (2018). They found that the increasing rate of lateral displacement in the diaphragm wall gradually decreases with the increasing length-to-width ratio. This can be attributed to the lateral displacement of the upper part of the pile being mainly restricted by the steel beams. When the length-to-width ratio increases, the length of the steel beam also increases. As the beam stiffness and the earth pressure are kept constant, the deformation of the beam at the middle plane area becomes larger based on the beam bending moment formula. In addition, the lateral displacements for the lower part of the pile are mainly restricted by the soil in the passive zone and the concrete slab. With the increase in the $L / B$, the lower part of the pile gradually reaches plane strain condition (Yu and Gong, 1999). In other words, there exists a critical length-to-width ratio, beyond which the spatial effect on the lower part of the pile behaviour can be neglected. Therefore, the displacements at the lower part of the pile gradually become stable with larger $L / B$ values.

By analogy, with increasing length-to-width ratio, the bending moments of the pile also increase as shown in Figure 11, while its increasing rate reduces. This is due to the fact that the restriction of the steel beam on the pile gradually becomes negligible with higher $L / B$ values.

Based on the preceding discussion, the design of the foundation pit should take into account the spatial effect. When the length-towidth ratio is relatively large, the spatial effect on the pile deformation at the centre of the foundation pit is insignificant. It is necessary to set the internal brace in the middle plane of the supporting structure to reduce lateral displacements of the pile.
In contrast, when the length-to-width ratio is relatively small, the mechanical deformation of the supporting structure is significantly restricted by the support at the sides of the foundation pit. Generally, fewer steel beams can be applied to save costs.

\section{Effect of the interval of the steel beam}

Jiang et al. (2007) pointed out that irregular arrangement of beams may cause too large stress and bending moments. In this part of the study, five scenarios using different numbers of steel beams $(n)$ are considered to study the influence of the beam interval on the lateral displacements and bending moments of representative supporting pile $\mathrm{A}$, and the results are shown in Figure 13. It should be noted that steel beams are evenly distributed along the depth in these five scenarios for the sake of simplicity. The results of the initial model with uneven distributions are shown as well for comparison.

As can be seen, with decreasing beam interval, the lateral displacements of the pile reduce exponentially. When the interval value reaches about $2.5 \mathrm{~m}(n=5)$, the lateral displacements of the pile tend to be stable, which means that it is no more economical to reduce the interval for the purpose of having less deformation of the pile. The authors further derive the maximum lateral displacement of pile A with increasing number of steel beams in Figure 14. As the figure shows, a logarithmic relationship is found, and this is consistent with the aforementioned optimisation of the beam interval from the economic perspective.

According to Figure 13, the bending moments of the pile decrease with decreasing beam interval. It should be noted that when the beam interval is more than $2.5 \mathrm{~m}$, the bending moments of the pile fluctuate significantly along the pile, which may damage the pile due to stress concentration. When the beam interval is less than $2.5 \mathrm{~m}$, the bending moments of the pile become uniform along the entire pile. In addition, when beams are installed at the top and bottom of the foundation pit only $(n=2)$, the inflection point of the bending moment occurs at about $1 \mathrm{~m}$ above the bottom of the foundation pit, which is different compared with other scenarios. This is related to the large deformation of the soil in the passive earth pressure zone. With decreasing beam interval, the inflection point of the bending moment distribution gradually returns to the bottom of the foundation pit. In other words, the distribution of the bending moment can be optimised by changing the beam interval in the design stage.

\section{Sensitivity analysis}

In the previous sections, the influence of geometrical parameters of the supporting structure on the model responses has been investigated. However, uncertainty of soil properties is inevitable due to the heterogeneity of the soil domain and limited borehole information based on in situ investigation. Therefore, it is necessary to study the effect of soil stiffness and shear strength on the supporting structure behaviour. In this section, sensitivity analysis (SA) is conducted to evaluate the relative importance of soil parameters in determining the model responses. 

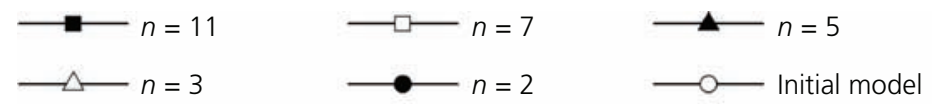

Lateral displacement: $\mathrm{mm}$

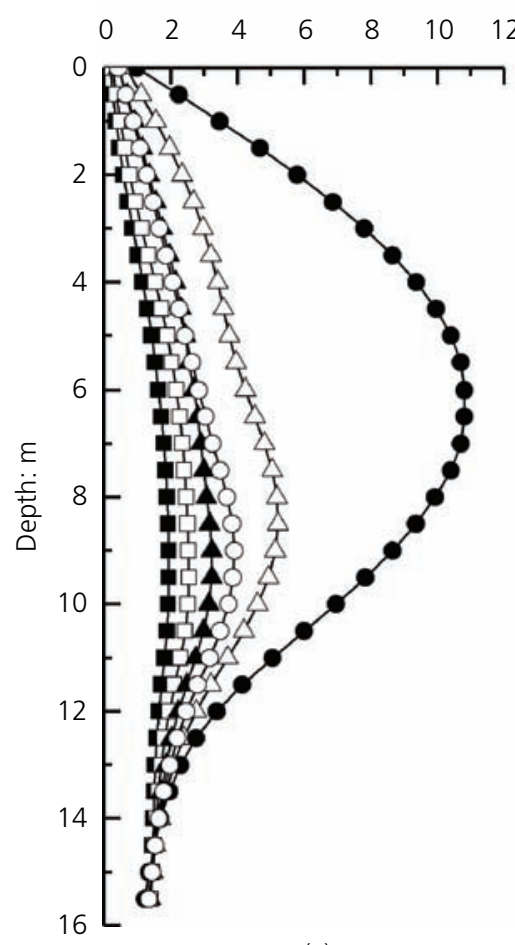

(a)

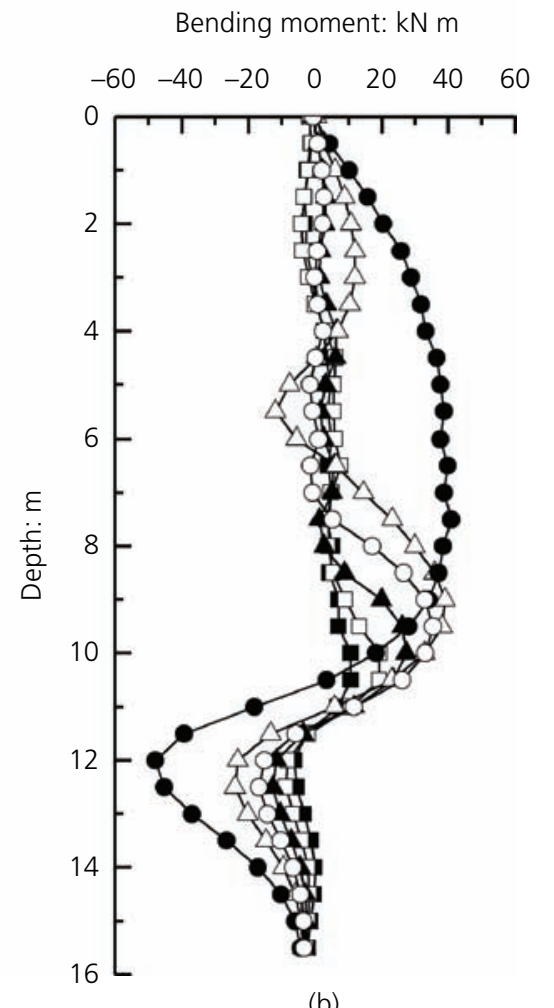

(b)

Figure 13. Effect of the beam interval on the (a) lateral displacements and (b) bending moments of the representative pile

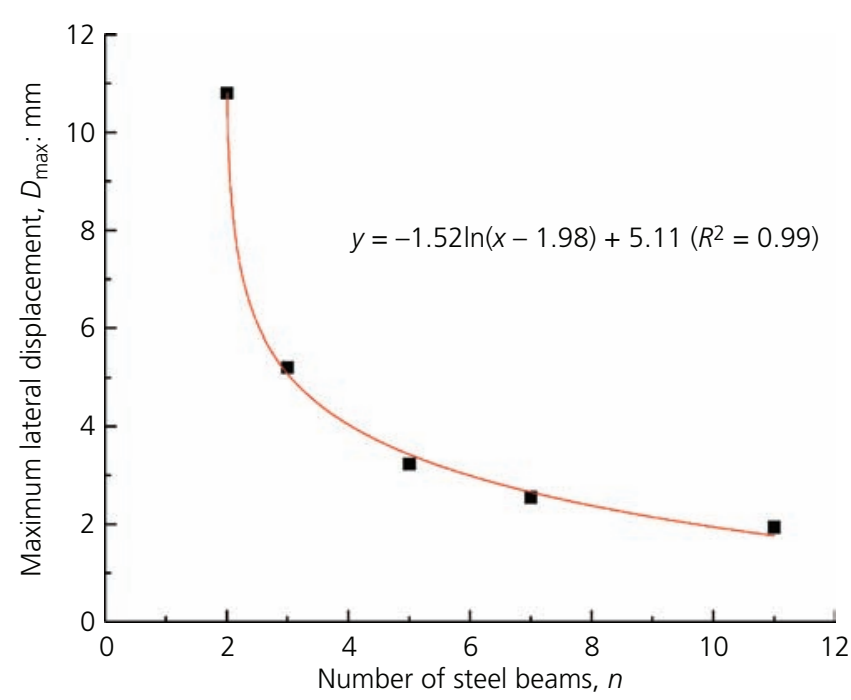

Figure 14. Effect of the beam interval on the maximum lateral displacement

\section{Global sensitivity analysis}

There are two main concepts of SA - namely, LSA and GSA. For LSA, the partial derivatives of the model response with respect to related input variables are evaluated at a given point in the parameter space. If the relationship between input and output values is non-linear, the sensitivity information obtained by this method is highly dependent on the given local point and step size in numerical calculation of the derivatives (Iott et al., 1985; Rohmer, 2014). Hence, it is questionable to apply the LSA result to the whole parameter space under consideration. Additionally, only one parameter is varied in each evaluation; the coupled effect between different parameters is not considered. While the GSA explores the whole input space of related parameters, the reliability of results is not affected by the nature of the model. Moreover, it evaluates the uncertainty contribution not only from the variation of a specific parameter itself but also from the correlated variations of other parameters. GSA can be applied to estimate accurately the sensitivity of parameters within the whole input space. In this paper, the variance-based method (Sobol, 1993) of GSA is applied to study the model response uncertainty due to the input parameter uncertainty; the total effect index $S_{T j}$ (Jansen, 1999) can be presented as 
1. $S_{\mathrm{T} j}=\frac{\left(\boldsymbol{y}_{\mathrm{B}}-\boldsymbol{y}_{C j}\right)^{T}\left(\boldsymbol{y}_{\mathrm{B}}-\boldsymbol{y}_{C j}\right)}{2 \boldsymbol{y}_{\mathrm{B}}^{T} \boldsymbol{y}_{\mathrm{B}}-2 n\left(\bar{y}_{\mathrm{B}}\right)^{2}}$

where $\mathbf{A}$ and $\mathbf{B}$ are two independent $(N, k)$ matrices, each containing $N$ random samples of the input parameter vector $\boldsymbol{Z}=$ $Z_{1}, Z_{2}, \ldots, Z_{k}$. For matrix $\mathbf{C}_{j}$, its columns are copied from matrix B except the $j$ th column copied from the corresponding column in A. $y_{\mathrm{A}}, \boldsymbol{y}_{\mathrm{B}}$ and $\boldsymbol{y}_{\mathrm{C} j}$ are vectors containing model evaluations for matrices $\mathbf{A}, \mathbf{B}$ and $\mathbf{C}_{j}$, respectively. $\bar{y}_{\mathrm{A}}$ and $\bar{y}_{\mathrm{B}}$ are the mean values estimated from the components of $\boldsymbol{y}_{\mathrm{A}}$ and $\boldsymbol{y}_{\mathrm{B}}$, respectively.

According to the soil layer distribution and geometry of the supporting structure, soil layers 2 and 4 are selected as the layers of interest. Subsequently, the elastic stiffness $\left(E_{2}, E_{4}\right)$, cohesion $\left(c_{2}\right.$, $\left.c_{4}\right)$ and friction angle $\left(\phi_{2}, \phi_{4}\right)$ in these two layers are considered uncertain soil parameters to conduct GSA. The corresponding ranges of these parameters are given in Table 3, which is based on engineering judgement and the Geological Engineering Handbook (GEH, 2018), while for the model responses, the maximum lateral displacement $\left(D_{\max }\right)$ and maximum bending moment $\left(M_{\max }\right)$ of the pile as well as the lateral displacement at top of the pile $\left(D_{\text {top }}\right)$ are selected, as these are a key system behaviour that should be maintained within the tolerance limit during construction.

\section{Metamodel}

The GSA adopted in this paper requires thousands of model evaluation (runs) to generate the input parameter matrix. In addition, the investigated foundation pit model constitutes a 3D FE simulation of a complex excavation process, which needs significant computation time for each single run. Therefore, it is reasonable to substitute the FE simulation model with a metamodel that provides appropriate responses at the predefined observation points. Within this framework, the authors followed the approach proposed by Buljak (2012) and Khaledi et al. (2014). Proper orthogonal decomposition combined with a radial basis function has been employed to construct the metamodel. By doing so, 80 sample points from the design space of input parameters are generated using the Latin hypercube sampling technique. After that, the corresponding outputs that are related to the lateral displacement and bending moment of the pile were computed directly by using the FE model. Thereafter, a metamodel is created based on these sets of input and output

Table 3. Lower and upper bounds of constitutive parameters for the MC model

\begin{tabular}{lcccc} 
Soil layer & Parameter & Lower bound & Upper bound & Unit \\
\hline Layer 2 & $E_{2}$ & 8 & 45 & $\mathrm{MPa}$ \\
& $C_{2}$ & 15 & 25 & $\mathrm{kPa}$ \\
\multirow{4}{*}{ Layer 4 } & $\phi_{2}$ & 17 & 24 & $\circ$ \\
& $E_{4}$ & 8 & 45 & $\mathrm{MPa}$ \\
& $C_{4}$ & 15 & 25 & $\mathrm{kPa}$ \\
& $\phi_{4}$ & 17 & 24 & $\circ$ \\
\end{tabular}

values. The accuracy of the constructed metamodel has been evaluated through additional 20 validation points and determined by the standard error measure $R^{2}$, which verifies the overall performance of the metamodel, where in the best approximation, $R^{2}$ is close to 1 . In this study, $R^{2}=0.96$.

\section{Results and discussion}

Figure 15 shows the GSA result with respect to the initial foundation pit model described in the section headed 'Numerical simulation'. As can be seen from the figure, the elastic stiffnesses of these two layers are the key parameters. $D_{\text {top }}$ is dominated by elastic stiffness in soil layer 2, as this layer is closer to the model surface. In contrast, as the maximum lateral displacement and bending moment of the pile are observed in soil layer $4, E_{4}$ is the key parameter in determining $D_{\max }$ and $M_{\max }$.

It is worth mentioning that cohesion and friction angle are key parameters in determining the yield surface in soil constitutive modelling. However, Figure 15 shows that $c$ and $\phi$ have negligible effect on the pile behaviour. The possible reason is that the lateral displacement of the supporting pile is small and both the active and passive earth pressures are not fully mobilised; thus, the soil stress does not reach the MC yield surface. The influence of soil strength is negligible, and the soil elastic stiffness dominates the system response. Therefore, it is valuable to study the soil elastic and plastic deformation during excavation in detail.

One of the models used to train the metamodel is selected, where $E_{2}=19.4 \mathrm{MPa}, c_{2}=17.1 \mathrm{kPa}, \phi_{2}=19.2^{\circ}, E_{4}=25.2 \mathrm{MPa}, c_{4}=$ $24.1 \mathrm{kPa}$ and $\phi_{4}=17.5^{\circ}$. Figure 16 (a) shows the variation in the $D_{\text {top }}$ and maximum plastic strain of the soil with reduction in the shear strength of soil layer 2. As seen, the plastic deformation in the entire domain is almost not affected by the shear strength in soil layer 2; this is related to the fact that the maximum plastic strain in layer 2 is less than 0.04 even with $50 \%$ reduction in $c_{2}$ and $\phi_{2}$. This coincides with the $D_{\text {top }}$ being not sensitive to $c_{2}$ and $\phi_{2}$.

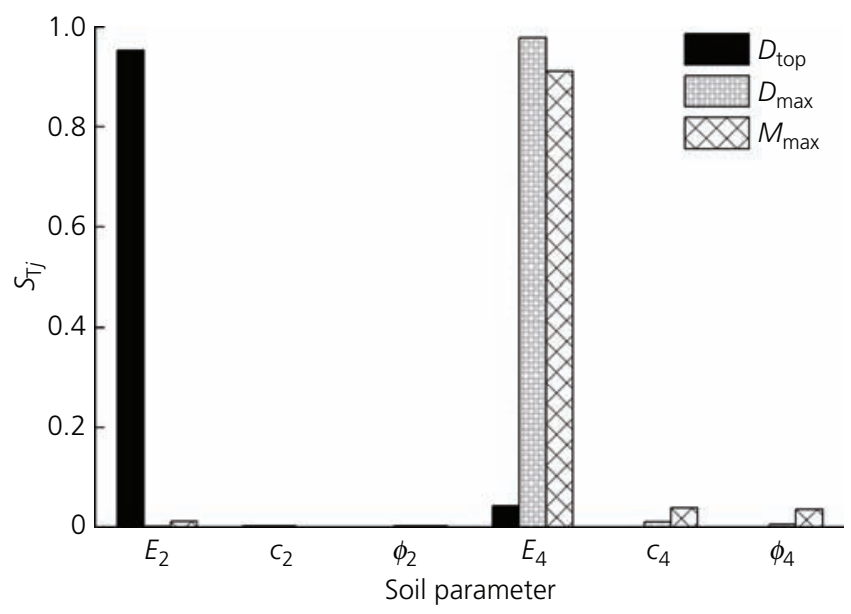

Figure 15. Result of GSA 


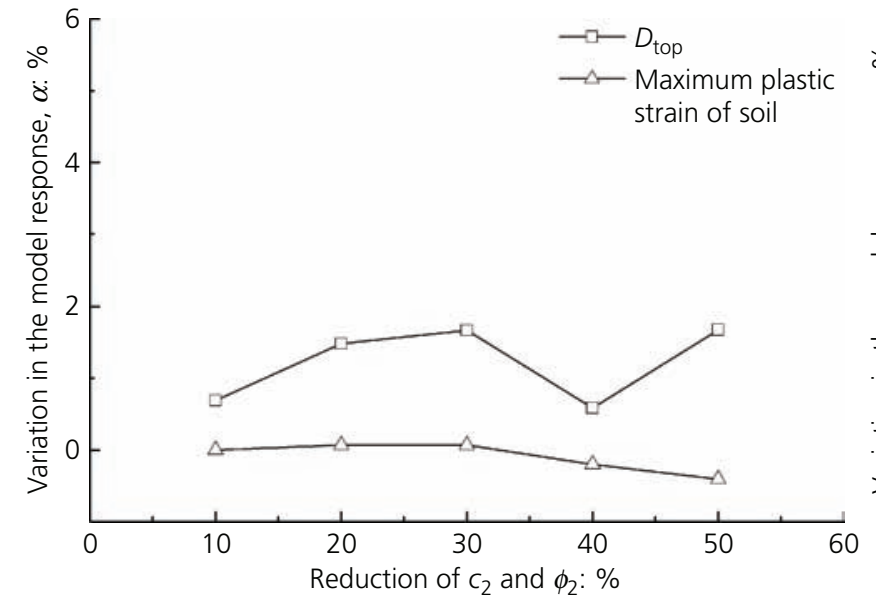

(a)

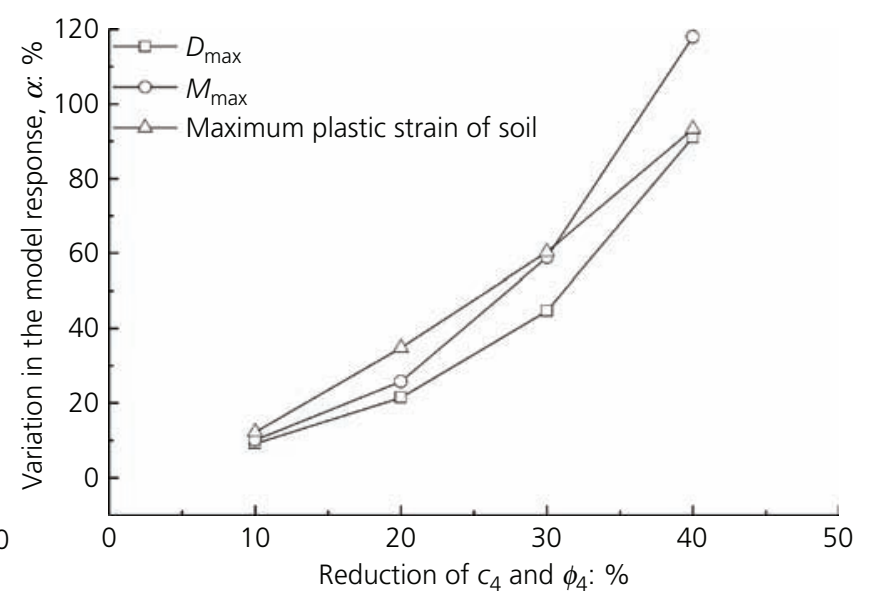

(b)

Figure 16. Effect of shear strength reduction for (a) soil layer 2 and (b) soil layer 4 on model responses

By analogy, Figure 16(b) shows the variation in the maximum lateral displacement and bending moment as well as maximum plastic deformation with reduction in $c_{4}$ and $\phi_{4}$. As seen, $D_{\max }$ and $M_{\max }$ increase rapidly with decreasing shear strength of soil layer 4, which coincides with the larger plastic strain observed around the foundation pit as shown in Figure 17.

According to the preceding discussion, almost all the soil deformations are within the elastic domain without shear strength reduction. This is consistent with the GSA result that elastic stiffness dominates the pile behaviour in the present study. This also implies that the adopted composite assembled recyclable supporting structure is able to control well the deformation of the surrounding soil with respect to the design criteria.

\section{Concluding remarks}

Based on the Niukouyu foundation pit project, this work studied the mechanical and deformation characteristics of the composite assembled recyclable supporting structure by way of a 3D FEM. The influencing geometrical factors that affect the structure behaviour were investigated, and the GSA of uncertain soil properties on system behaviour was carried out. Based on the analyses performed in the present study, the following conclusions can be outlined.
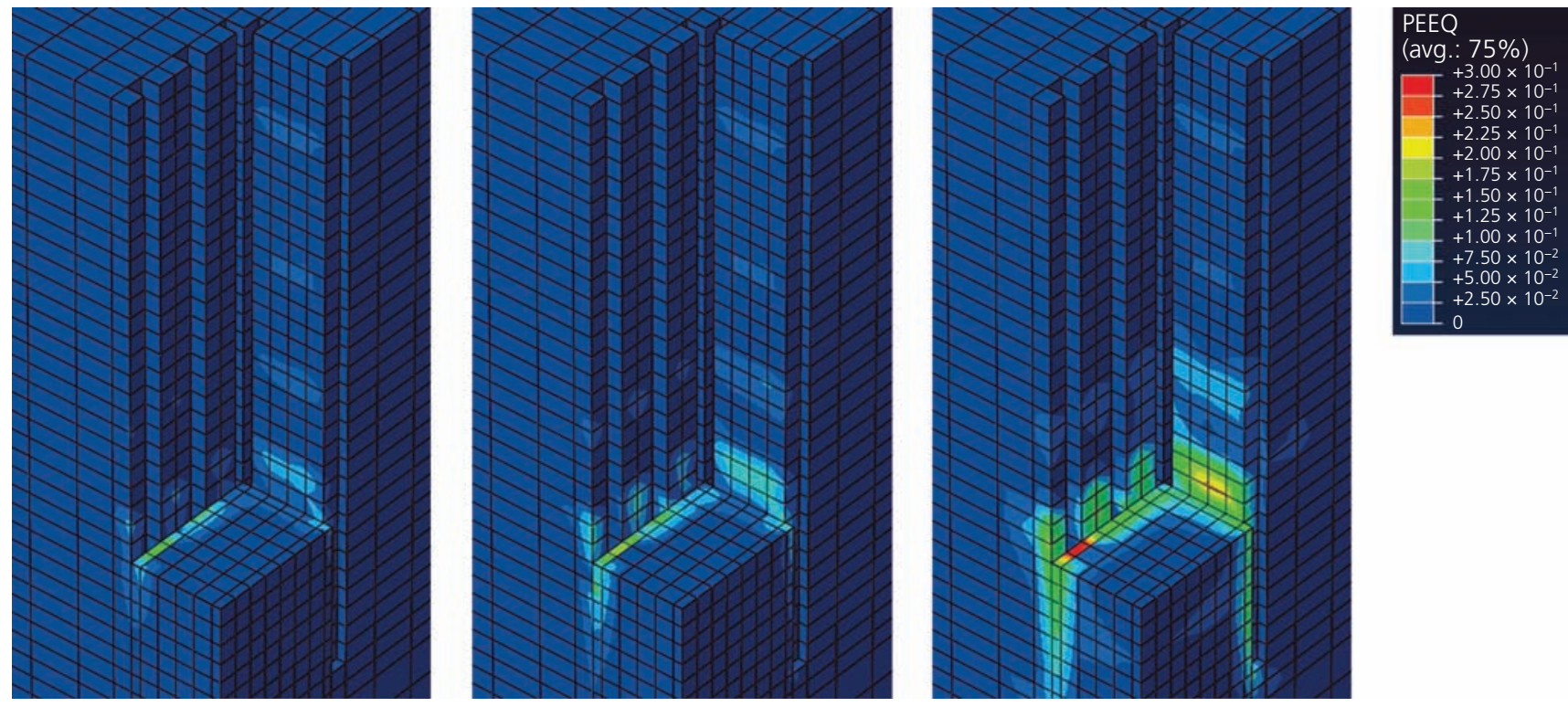

Figure 17. Influence of shear strength reduction for soil layer 4 on soil plastic strain distribution: initial model with maximum plastic strain of 0.15 (left); $20 \%$ reduction in $c_{4}$ and $\phi_{4}$ with maximum plastic strain of 0.20 (middle); $40 \%$ reduction in $c_{4}$ and $\phi_{4}$ with maximum plastic strain of 0.29 (right). Peeq, equivalent plastic strain 
- The lateral displacements of the supporting pile have an 'inward' deformation mode. The range of the maximum lateral displacement of the representative pile is $0.023-0.12 \%$ $H_{\mathrm{e}}\left(H_{\mathrm{e}}\right.$ represents the foundation pit depth), which is slightly less than that using a traditional supporting structure (more than $0.2 \% H_{\mathrm{e}}$ ). The composite assembled recyclable supporting structure can effectively control the deformation of the foundation pit with respect to design criteria.

- With increasing foundation pit depth, length-to-width ratio and beam interval, the lateral displacements and bending moments of the pile gradually increase. Both the maximum lateral displacement and bending moment occur at about $0.6 H_{\mathrm{p}}\left(H_{\mathrm{p}}\right.$ represents the length of the pile) below the ground surface. An increasing length-to-width ratio of the excavation induces larger lateral displacements at the upper part of the pile. When the steel beam interval value reduces to about $2.5 \mathrm{~m}$, the lateral displacements of the pile tend to be stable; it is not more economical to utilise more beams for the purpose of having less deformation of the supporting structure.

- The GSA result indicates that soil elastic stiffness dominates the mechanical and deformation characteristics of the supporting structure due to the fact that the lateral displacement of the supporting pile is small and both the active and passive earth pressures are not fully mobilised. Thus, the soil stress does not reach the MC yield surface. Nevertheless, the GSA method can be applied in any other problem where uncertainties of soil constitutive model parameters need to be evaluated.

\section{Acknowledgements}

This research has been supported by the Science and Technology Project of Tibet Autonomous Region (Number XZ201801-GB-07), the Program for Guangdong Introducing Innovative and Entrepreneurial Teams (Number 2016ZT06N340) and the Guangdong Basic and Applied Basic Research Foundation (Number 2019A1515111172). These supports are gratefully acknowledged.

\section{REFERENCES}

Blackburn J and Finno R (2007) Three-dimensional responses observed in an internally braced excavation in soft clay. Journal of Geotechnical and Geoenvironmental Engineering 133(11): 1364-1373, https://doi. org/10.1061/(ASCE)1090-0241(2007)133:11(1364).

Buljak V (2012) Inverse Analysis with Model Reduction: Proper Orthogonal Decomposition in Structural Mechanics. Springer, Berlin, Germany.

Cheng C and Likitlersuang S (2018) Underground excavation behavior in Bangkok using three-dimensional finite element method. Computers and Geotechnics 95: 68-81, https://doi.org/10.1016/j.compgeo.2017.09.016.

Clough GW and O'Rourke TD (1990) Construction induced movements of in situ walls. In Design and Performance of Earth Retaining Structures (Lambe P and Hansen LA (eds)). American Society of Civil Engineers, New York, NY, USA, pp. 439-470.

Finno RJ, Blackburn JT and Roboski JF (2007) Three-dimensional effects for supported excavations in clay. Journal of Geotechnical and Geoenvironmental Engineering 133(1): 30-36, https://doi.org/10.1061/ (ASCE)1090-0241(2007)133:1(30).

GEH (Geological Engineering Handbook) (2018) Geological Engineering Handbook. China Architecture and Building Press, Beijing, China (in Chinese).
Guo C, Wang R, Lin P and Wang F (2020) Numerical analyses of a prefabricated retaining system for foundation pits in silt soils. Geotechnical Research 7(3): 173-190, https://doi.org/10.1680/jgere.20.00015.

Hsieh PG and Chien SC (2018) Numerical investigation of the efficiency of buttress walls in reducing the diaphragm wall deflection by deep excavation. In Proceedings of the 2nd International Symposium on Asia Urban GeoEngineering (Chen R, Zheng G and Ou C (eds)). Springer, Singapore, pp. 676-689.

Hsiung B, Yang K, Aila W and Ge L (2018) Evaluation of the wall deflections of a deep excavation in Central Jakarta using threedimensional modeling. Tunnelling and Underground Space Technology 72: 84-96, https://doi.org/10.1016/j.tust.2017.11.013.

lott J, Haftka R and Adelman H (1985) Selecting Step Sizes in Sensitivity Analysis by Finite Differences. National Aeronautics and Space Administration, Scientific and Technical Information Branch, Washington, DC, USA, NASA Technical Memorandum 86383.

Jansen M (1999) Analysis of variance designs for model output. Computer Physics Communications 117(1-2): 35-43, https://doi.org/ 10.1016/S0010-4655(98)00154-4.

Jiang X, Zong J and Sun L (2007) Construction monitoring and numerical simulation for a deep excavation in Tianjin. China Civil Engineering Journal 40(2): 120-125 (in Chinese).

Khaledi K, Miro S, König M and Schanz T (2014) Robust and reliable metamodels for mechanized tunnel simulations. Computers and Geotechnics 61: 1-12, https://doi.org/10.1016/j.compgeo.2014.04.005.

Knabe T, Schweiger H and Schanz T (2012) Calibration of constitutive parameters by inverse analysis for a geotechnical boundary problem. Canadian Geotechnical Journal 49(2): 170-183, https://doi.org/10. 1139/t11-091.

Li D, Li Z and Tang D (2015) Three-dimensional effects on deformation of deep excavations. Proceedings of the Institution of Civil Engineers Geotechnical Engineering 168(6): 551-562, https://doi.org/10.1680/ jgeen.15.00042.

Liu G, Jiang R, Ng C and Hong Y (2011) Deformation characteristics of a $38 \mathrm{~m}$ deep excavation in soft clay. Canadian Geotechnical Journal 48(12): 1817-1828, https://doi.org/10.1139/t11-075.

Miro S, Hartmann D and Schanz T (2014) Global sensitivity analysis for subsoil parameter estimation in mechanized tunneling. Computers and Geotechnics 56: 80-88, https://doi.org/10.1016/j.compgeo.2013.11.003.

Ou C, Hsieh P and Chiou D (1993) Characteristics of ground surface settlement during excavation. Canadian Geotechnical Journal 30(5): 758-767, https://doi.org/10.1139/t93-068.

Pan Y, Fang H and Li B (2019) Stability analysis and full-scale test of a new recyclable supporting structure for underground ecological granaries. Engineering Structures 192: 205-219, https://doi.org/10. 1016/j.engstruct.2019.04.087.

Roboski J (2004) Three-dimensional Performance and Analyses of Deep Excavations. $\mathrm{PhD}$ thesis, Northwestern University, Evanston, IL, USA.

Rohmer J (2014) Dynamic sensitivity analysis of long-running landslide models through basis set expansion and meta-modelling. Natural Hazards 73(1): 5-22, https://doi.org/10.1007/s11069-012-0536-3.

Sobol I (1993) Sensitivity estimates for nonlinear mathematical models. Mathematical Modelling and Computational Experiment 1: 407-414.

Wang J (2018) Numerical Simulation Analysis of Ellipse Retaining Structure in Deep Foundation Pit. Master's thesis, Zhengzhou University, Zhengzhou, China (in Chinese).

Wang F, Fang H, Pan Y and Zhao P (2018) Design and Construction Method of Flexible Prefabricated Recoverable Rectangular Working Shaft Support Structure. Chinese Patent CN109056746a, Dec.

Xu Z, Wang J and Wang W (2008) Deformation characteristics of underground continuous wall in deep foundation pit in Shanghai area. China Civil Engineering Journal 41(8): 82-87 (in Chinese).

Xu S, Hou Y and Liu M (2018) Analysis of ground surface deformation and retaining wall deflection characteristics under excavation of deep 
Geotechnical Research

Volume 7 Issue 4
Mechanical and deformation

characteristics of composite assembled

supporting structure

Guo, Ye, Zhao and Wang foundation pit of station in Tianjin subway line 6. Journal of Beijing Jiaotong University 42(1): 25-33 (in Chinese).

Yu J and Gong X (1999) Spatial behavior analysis of deep excavation. Chinese Journal of Geotechnical Engineering 21(1): 21-25.

Zhao C, Lavasan AA, Barciaga T et al. (2015) Model validation and calibration via back analysis for mechanized tunnel simulations - the
Western Scheldt tunnel case. Computers and Geotechnics 69: 601-614, https://doi.org/10.1016/j.compgeo.2015.07.003.

Zhao C, Lavasan AA, Hölter R and Schanz T (2018) Mechanized tunneling induced building settlements and design of optimal monitoring strategies based on sensitivity field. Computers and Geotechnics $\mathbf{9 7}$ : 246-260, https://doi.org/10.1016/j.compgeo.2018.01.007.

\section{How can you contribute?}

To discuss this paper, please submit up to 500 words to the editor at journals@ice.org.uk. Your contribution will be forwarded to the author(s) for a reply and, if considered appropriate by the editorial board, it will be published as a discussion in a future issue of the journal. 